\title{
Tuberculoma with phlegmon-like symptoms mimicking soft tissue sarcoma in the wrist: A case report
}

\author{
KAZUHIKO HASHIMOTO, SHUNJI NISHIMURA, NAOHIRO OKA, RYOSUKE KAKINOKI and MASAO AKAGI \\ Department of Orthopedic Surgery, Kindai University Hospital, Osaka-Sayama, Osaka 589-8511, Japan
}

Received May 15, 2018; Accepted June 11, 2018

DOI: $10.3892 / \mathrm{mco} .2018 .1652$

\begin{abstract}
Despite the increasing incidence of tuberculosis, even in developed countries like Japan, tuberculoma is a relatively uncommon disease. Furthermore, given the rarity of tuberculoma, a definitive diagnosis is often delayed. We herein present the case of a 79-year-old man who presented with an erythematous and warm mass in the left forearm. Radiography revealed calcification of the wrist's volar side, and magnetic resonance imaging revealed a mosaic pattern at the lesion. Soft tissue sarcoma of the wrist was suspected, and an incisional biopsy was performed, which revealed numerous yellow rice bodies. A rapid pathological evaluation revealed caseous necrosis and Langhans giant cells, and a histological evaluation confirmed the diagnosis of tuberculoma. All the rice bodies were resected and the patient received postoperative antibiotic treatment with pyrazinamide, isoniazid, rifampicin and ethambutol. However, the patient developed hepatic insufficiency during treatment, and the regimen was discontinued. The patient had not experienced recurrence 1 year after the treatment. In conclusion, tuberculoma should be considered in the differential diagnosis of a wrist mass mimicking an inflamed soft tissue tumor.
\end{abstract}

\section{Introduction}

Infection with Mycobacterium tuberculosis may lead to the development of masses in the lungs (1) or musculoskeletal sites, which are often referred to as tuberculomas (2). When tuberculoma develops in the wrist, it often induces an inflammatory reaction, such as tenosynovitis, due to the related friction (3). Cases of wrist tuberculoma with tenosynovitis are relatively uncommon, but are becoming more frequent due to the increasing incidence of tuberculosis worldwide (3-5). However, to the best of our knowledge, no case reports to date have described tuberculomas with phlegmon-like symptoms. Therefore, we herein report an uncommon case of

Correspondence to: Dr Kazuhiko Hashimoto, Department of Orthopedic Surgery, Kindai University Hospital, 377-2 Ohno-Higashi, Osaka-Sayama, Osaka 589-8511, Japan E-mail: hazzhiko@med.kindai.ac.jp

Key words: tuberculoma, phlegmon, wrist, rice body, sarcoma wrist tuberculoma with phlegmon-like symptoms and review the related literature.

\section{Case report}

A 79-year old man noticed a swelling in his left wrist and forearm 3 months before he visited the Kindai University Hospital (Osaka-Sayama, Japan), although he did not report experiencing wrist pain. The patient did not have any significant medical history and had never had tuberculosis. A physical examination revealed that his left wrist was erythematous and felt warm to the touch (Fig. 1A), although the range of motion of the wrist was normal, there was no numbness of the hand or fingers, and the muscle strength was also normal. The blood testing results were normal, with no evidence of an inflammatory reaction (Table $\mathrm{I}$ ). The $\mathrm{C}$-reactive protein concentration was $0.21 \mathrm{mg} / \mathrm{dl}$, with a white blood cell count of $8,500 / \mu \mathrm{l}$ and an erythrocyte sedimentation rate of $4 \mathrm{~mm} / \mathrm{h}$.

Radiography revealed lytic regions at the radius and scaphoid, as well as calcification in the volar side of the wrist (Fig. 1B and C). Magnetic resonance imaging revealed a mosaic mass that involved the flexor tendons in the T1-weighted and T2-weighed images (Fig. 2A-C), with a high-intensity area in the T2-weighed image (Fig. 2B). Incisional biopsy was performed and numerous rice bodies were discovered in the wrist (Fig. 2D). A rapid pathological evaluation revealed necrosis, and as many rice bodies as possible were removed (Fig. 2E). A histological evaluation of the resected specimens revealed caseous necrosis and Langhans giant cells (Fig. 3A and B). After consulting the Infection Prevention and Control Team, the patient received postoperative antibiotic treatment (pyrazinamide 1,100 mg/day, isoniazid $200 \mathrm{mg} /$ day, rifampicin $450 \mathrm{mg} /$ day and ethambutol $1,000 \mathrm{mg} / \mathrm{day})$. The treatment was scheduled for a 2-month period, although it was discontinued as the patient developed hepatic insufficiency after 2 weeks of treatment (aspartate transaminase level 1,038 U/1 and alanine transaminase level $1,506 \mathrm{U} / \mathrm{l})$. After the treatment was stopped, the patient's hepatic function normalized (aspartate transaminase $19 \mathrm{U} / \mathrm{l}$ and alanine transaminase $21 \mathrm{U} / \mathrm{l})$, and no recurrence was detected at 1 year after treatment.

\section{Discussion}

Musculoskeletal tuberculoma is relatively uncommon (6), although it may result in the formation of rice bodies and the 
development of tenosynovitis in the wrists (3-6). However, there are no reports describing phlegmon-like symptoms (redness and heat), which were observed in the present case. Previous studies have indicated that wrist tuberculoma predominantly affects men and predominantly involves the right wrist (7), with overuse of the dominant hand potentially inducing tuberculoma with tenosynovitis (8). However, our patient reported that he had a dominant right hand, while the lesion developed in his left wrist. In general, redness and heat are not common signs of tuberculoma, which typically involves a cold abscess (9). In the present case, the phlegmon-like symptoms were likely caused by the friction between the flexor tendons and the lesion, as a subcutaneous infection was excluded based on the absence of inflammatory markers in the blood test results. Therefore, it is important for physicians to be aware that a wrist tuberculoma may manifest with phlegmon-like symptoms.

The route of infection may involve direct invasion or a hematogenous spread from a distant primary site, such as the lungs, lymph nodes, bones, soft tissues, or genitourinary tract (10). This condition should be suspected in cases that involve trauma, overuse of the joint, older age, malnutrition, and decreased immune function (11). Although the mechanism of infection in this patient was not elucidated, he was an older man with decreased immune function, and it is possible that the infection involved the lymph nodes.

Rice bodies were first described by Reise in 1895 (12) and are observed in $\sim 50 \%$ of wrist tuberculomas (7). These objects macroscopically resemble shiny white rice grains, whereas microscopically they consist of an inner amorphous core of acidophilic material surrounded by fibrin and collagen (5). Their pathogenesis is unclear, although they may originate from microinfarcted synovium and induce synovial shedding with subsequent encasement by fibrin derived from the synovial fluid. It is also possible that early rice bodies form de novo and independently of synovial elements, with progressive enlargement that is driven by fibrin aggregation $(5,13)$. In this context, the disease progresses through distinct histopathological stages that are dependent on the status, the patient's immune function, and the virulence of the infecting pathogen $(7,11)$. The first stage involves replacement of the tendon by granulation tissue, which is followed by the sheath being obliterated by fibrous tissue, and finally caseation leading to the appearance of rice bodies. At this point, the tendons may only consist of a few strands of tissue and are prone to spontaneous rupture $(7,11)$. Our patient was likely between the third and final stages. Previous studies have indicated that surgical intervention should be avoided, as rice bodies per se can be harmless $(4,7)$; however, surgical treatment was performed in the present case due to the phlegmon-like symptoms and the absence of a definitive diagnosis.

The diagnosis of tuberculous tenosynovitis is often delayed, as the symptoms may mimic those of atypical mycobacterial infections, tuberculosis, systemic lupus erythematosus, brucellosis, foreign body tendonitis, osteoarthritis and rheumatoid arthritis $(5,7)$. Thus, the diagnosis must be confirmed by biopsy and culture of the histopathological specimens, although these steps require a significant length of time and may delay diagnosis and treatment. Therefore,
Table I. Blood test results.

\begin{tabular}{lcc}
\hline Tests & $\begin{array}{c}\text { Normal } \\
\text { value }\end{array}$ & $\begin{array}{c}\text { Preoperative } \\
\text { values }\end{array}$ \\
\hline C-reactive protein $(\mathrm{mg} / \mathrm{dl})$ & $0.0-0.1$ & 0.21 \\
Aspartate transaminase $(\mathrm{U} / \mathrm{l})$ & $13.0-30.0$ & 23 \\
Alanine transaminase $(\mathrm{U} / \mathrm{l})$ & $7.0-23.0$ & 22 \\
White blood cells $\left(\mathrm{x} 10^{3} \mu \mathrm{l}\right)$ & $3.3-8.6$ & 8.5 \\
Hemoglobin $(\mathrm{g} / \mathrm{dl})$ & $11.6-14.8$ & 14.8 \\
Platelets $\left(\mathrm{x} 10^{4} \mu \mathrm{l}\right)$ & $15.8-34.8$ & 30.1 \\
Blood urea nitrogen $(\mathrm{mg} / \mathrm{dl})$ & $8.0-20.0$ & 14 \\
Creatinine $(\mathrm{mg} / \mathrm{dl})$ & $0.5-0.8$ & 0.65 \\
Sodium $(\mathrm{mEq} / \mathrm{l})$ & $138.0-145.0$ & 139 \\
Potassium $(\mathrm{mEq} / \mathrm{l})$ & $3.6-4.8$ & 4.3 \\
Chlorine $(\mathrm{mEq} / \mathrm{l})$ & $101.0-108.0$ & 104 \\
Total protein $(\mathrm{g} / \mathrm{dl})$ & $6.6-8.1$ & 5.9 \\
Albumin $(\mathrm{g} / \mathrm{dl})$ & $4.1-5.1$ & 3.3
\end{tabular}
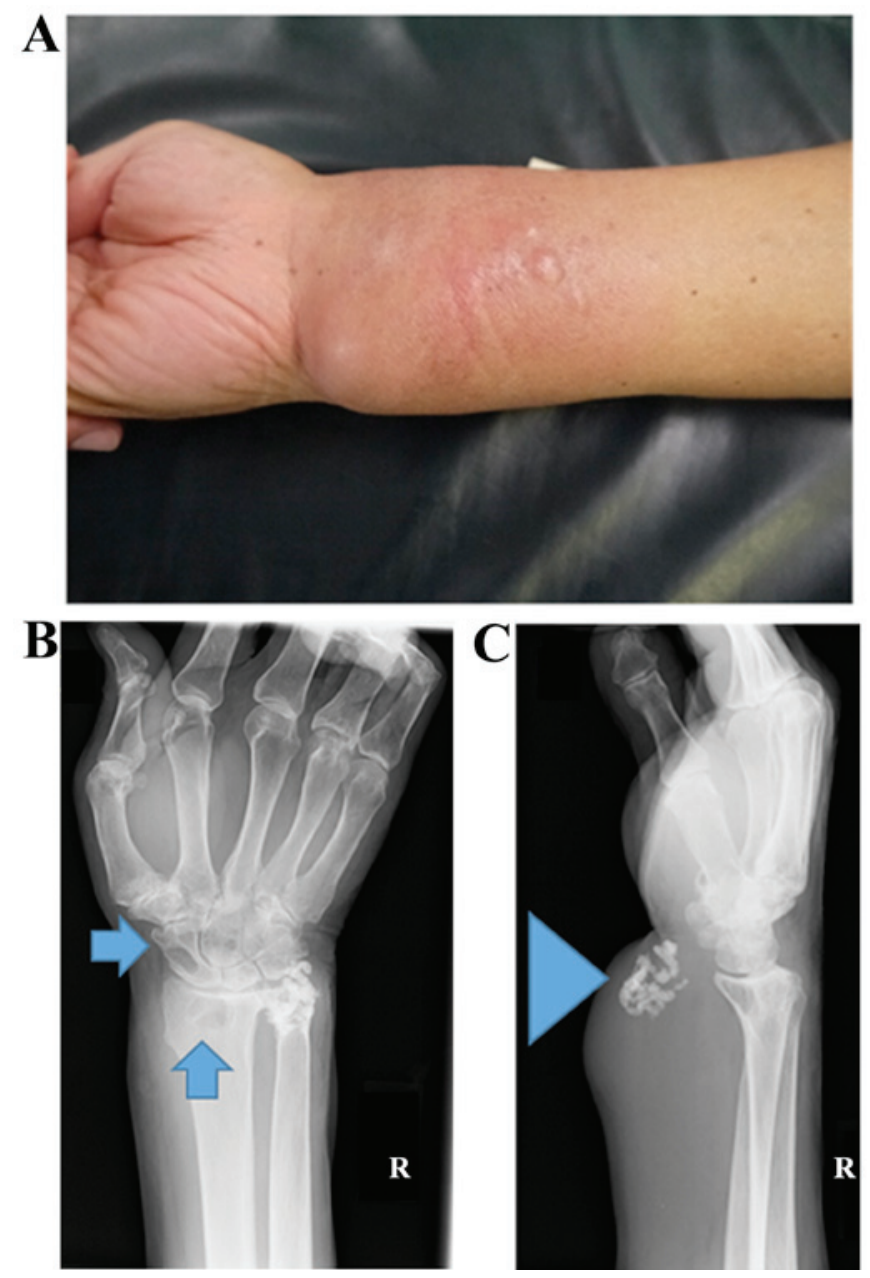

Figure 1. Physical and radiological findings. (A) The volar surface of the left wrist appeared red and swollen. (B) Radiography in the coronal plane revealed lytic regions at the radius and scaphoid (arrows), while (C) radiography in the sagittal plane revealed calcifications of the volar side (arrowheads).

when the tentative diagnosis is tuberculous tenosynovitis, antibiotic treatment should be started while waiting for the 

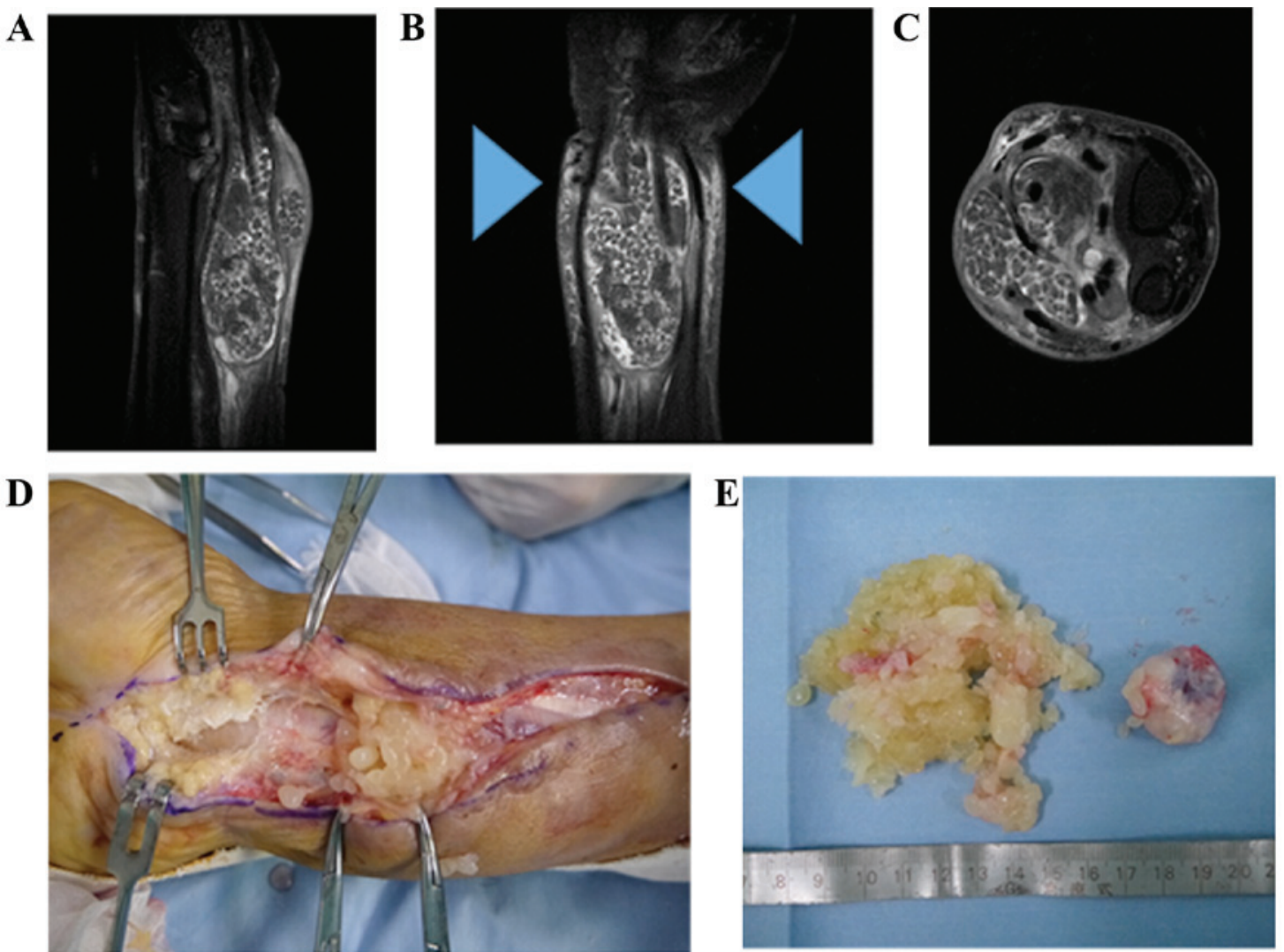

Figure 2. Magnetic resonance imaging (MRI) and surgical findings. Images are shown for (A) sagittal T1-weighed MRI, (B) coronal T2-weighed MRI and (C) cross-sectional T1-weighted MR. Blue arrowheads indicate high-intensity subcutaneous lesions. (D and E) Intraoperative findings, with numerous removed rice bodies.
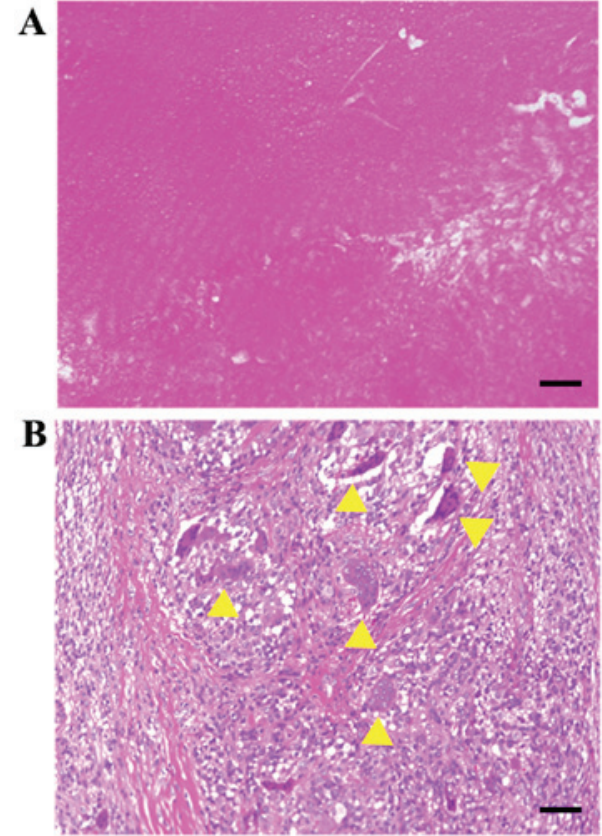

Figure 3. Histological findings. The histological examination revealed (A) caseous necrosis and (B) Langhans giant cells (arrowheads). Hematoxylin and eosin staining; magnification, $\mathrm{x} 200$; scale bar, $100 \mu \mathrm{m}$.

results $(7,14)$. However, anti-tuberculosis drugs often induce hepatic dysfunction $(15,16)$, with elevation of biliary or hepatic enzymes (e.g., aspartate transaminase and alanine trans- aminase) being common in elderly patients (16). Thus, careful observation is necessary when using anti-tuberculosis drugs to treat elderly patients, as in the present case.

The recommended surgical technique involves decompression of the median nerve when this condition is associated with clinical symptoms of carpal tunnel syndrome (17). Local recurrence is possible, and $\sim 50 \%$ of the cases develop recurrence within 1 year (18). However, our patient did not experience recurrence within the first year, which may be attributed to the rapid diagnosis and treatment.

In conclusion, we encountered a case of tuberculoma with phlegmon-like symptoms in an elderly patient. Therefore, tuberculoma should be considered in the differential diagnosis of patients with an erythematous, warm and swollen wrist. Rapid diagnosis and treatment are required to ensure good outcomes in such cases.

\section{Acknowledgements}

Not applicable.

\section{Funding}

No funding was received.

\section{Availability of data and materials}

All data presented in this study are available from the corresponding author upon reasonable request. 


\section{Authors' contributions}

Data acquisition: KH, SN, NO and RK. Data analysis: KH, SN NO and MA. Manuscript preparation: KH and MA. All authors have read and approved the final version of this manuscript.

\section{Ethics approval and consent to participate}

Not applicable.

\section{Patient consent for publication}

The patient provided informed consent for the publication of the case details and associated images.

\section{Competing interests}

The authors declare that they have no competing interests to disclose.

\section{References}

1. Li CR, Li YZ, Li YM and Zheng YS: Dynamic and contrast enhanced CT imaging of lung carcinoma, pulmonary tuberculoma and inflammatory pseudotumor. Eur Rev Med Pharmacol Sci 21: 1588-1592, 2017.

2. Ju HB, Guo DM and Chen FF: Intramedullary cervical tuberculoma: A case report with note on surgical management. Int Surg 100: 133-136, 2015.

3. Anoumou MN, Kouame M, Daix T and Yepie A: Tuberculosis tenosynovitis of the flexor tendons in the wrist: A case report. Acta Orthop Traumatol Turc 48: 690-692, 2014.

4. Woon CY, Phoon ES, Lee JY, Puhaindran ME, Peng YP and Teoh LC: Rice bodies, millet seeds and melon seeds in tuberculous tenosynovitis of the hand and wrist. Ann Plast Surg 66: 610-617, 2011.
5. Ergun T, Lakadamyali $\mathrm{H}$ and Aydin O: Multiple rice body formation accompanying the chronic nonspecific tenosynovitis of flexor tendons of the wrist. Radiat Med 26: 545-548, 2008.

6. Sbai MA, Benzarti S, Bouzaidi K, Sbei F and Maalla R: A rare localization of tuberculosis of the wrist: The scapholunate joint. Int J Mycobacteriol 4: 161-164, 2015.

7. Baidoo PK, Baddoo D, Ocloo A, Agbley D, Lartey S and Baddoo NA: Tuberculous tenosynovitis of the flexor tendons of the wrist: A case report. BMC Res Notes 11: 238, 2018.

8. Hoffman KL, Bergman AG, Hoffman DK and Harris DP: Tuberculous tenosynovitis of the flexor tendons of the wrist: MR imaging with pathologic correlation. Skeletal Radiol 25: 186-188, 1996.

9. Kouassi KJ, Yao LB, Sery BJLN, M'bra KI, Krah KL, Lohourou GF and Kodo M: Dorsolumbar cold abscess revealing Pott's disease. Pan Afr Med J 27: 2, 2017.

10. Higuchi S, Ishihara S, Kobayashi $\mathrm{H}$ and Arai T: A mass lesion of the wrist: A rare manifestation of tuberculosis. Intern Med 47: 313-316, 2008.

11. Lall H, Nag SK, Jain VK, Khare R and Mittal D: Tuberculous extensor tenosynovitis of the wrist with extensor pollicis longus rupture: A case report. J Med Case Reports 3: 142, 2009.

12. Reise H: Die Reiskorpschen in tuberculserkrankensynovalsacken. Dtsch Z Chir 42: 1, 1895 (In German).

13. Popert AJ, Scott DL, Wainwright AC, Walton KW, Williamson N and Chapman JH: Frequency of occurrence, mode of development and significance or rice bodies in rheumatoid joints. Ann Rheum Dis 41: 109-117, 1982.

14. Wali H, Al-Khuwaitir S and Hafeez MA: Compound palmar ganglion: A case report and literature review. Ann Saudi Med 6: 55-59, 1986

15. Cao J, Mi Y, Shi C, Bian Y, Huang C, Ye Z, Liu L and Miao L: First-line anti-tuberculosis drugs induce hepatotoxicity: A novel mechanism based on a urinary metabolomics platform. Biochem Biophys Res Commun 497: 485-491, 2018.

16. Chang LY, Lee CH, Chang CH, Lee MC, Lee MR, Wang JY and Lee LN: Acute biliary events during anti-tuberculosis treatment: Hospital case series and a nationwide cohort study. BMC Infect Dis 18: 64, 2018.

17. Jaovisidha S, Chen C, Ryu KN, Siriwongpairat P, Pekanan P, Sartoris DJ and Resnick D: Tuberculous tenosynovitis and bursitis: Imaging findings in 21 cases. Radiology 201: 507-513, 1996.

18. Regnard PJ, Barry P and Isselin J: Mycobacterial tenosynovitis of the flexor tendons of the hand. A report of five cases: J Hand Surg 21: 351-354, 1996. 